\title{
Ergonomic Stress Index (ESI) v 2.0 for Recognition and Assessment of Ergonomic Stressors in VDT Workstations
}

\author{
Namrata Arora Charpe* and Vandana Kaushik \\ Department of Ergonomics, Banasthali Vidyapith, India \\ *Corresponding Author: Namrata Arora Charpe, Department of Ergonomics, \\ Banasthali Vidyapith, India.
}

Received: January 30, 2020

Published: May 25, 2020

(C) All rights are reserved by Namrata Arora

Charpe and Vandana Kaushik .

\begin{abstract}
The study aimed at revising the research tool Ergonomic Stress Index (ESI) developed by Charpe and Kaushik [1], designed to assess the magnitude of ergonomic stress among operators in the VDT workstations. The study was conducted in two phases. In the first phase, the tool ESI with 27 items was administered on 200 subjects for pilot study. Most relevant items were retained after item analysis. In the second phase, the tool with selected 20 items was administered on a sample of 1000 VDT operators, out of which 839 subjects were available for the administration for test retest reliability estimation. The tool was analysed statistically and was found to be highly consistent internally $(r=0.94)$ and highly reliable for repeated administrations $(r=0.93)$.

Keywords: Ergonomic Risk Factors; Static work; Ergonomic Stress Index (ESI); VDT Workstation; Computer Operators
\end{abstract}

\section{Introduction}

VDT workstations have a peculiar setup for sedentary work, posing a considerable amount of stress on the worker. The stress arises from a number of factors like static or awkward postures, repetitive movement of wrists and fingers, continuous gaze on the monitor, and many such factors. It is important to address these risk factors in order to reduce the physical, affective, temporal and cognitive costs of work and keep the workers in best of their wellbeing.

Working on a VDT is characterised by its static nature and repetitive movements of fingers and wrists. In prolonged sitting, the worker is subject to continuous stress on almost all postural muscles which in turn makes them less efficient, making them work harder all the time. In awkward postures, the joints are more susceptible to injuries and the muscles are left with lesser capacity of generating and exerting force. Studies suggest that no office in the contemporary work world operates without VDTs. On one hand VDTs take productivity and efficiency to next level, but at the same time exposes the operators to various types of ergonomic risk factors. Ergonomic Stress Index [1] was developed to measure the level of ergonomic stress posed in terms of intensity of the pain symptoms experienced by workers while working on a VDTs for prolonged periods. The study aimed at an attempt to revise ESI in order to have a more reliable and comprehensive version of the tool.

\section{Literature Review}

Bridger [2] reported that the physical demands of much of daily life nowadays bear no resemblance to those of our ancestors and are incompatible with what our bodies are designed to do. Charpe and Gupta [3] reported that VDT operators experience higher levels of stress than any other group of workers, because of the sedentary nature of work involved which is considered to be tedious, monotonous and demanding. According to Shuval and Donchin [4] upper extremity musculoskeletal disorders and ergonomic research have not focused enough on the Hi-Tech industry. Even with the .com crash, this industry remains a major force in the world economy. VDT work in the Hi-Tech industry has unique risk factors, which might lead to specific needs for intervention. An assessment of VDU workplace risk factors by Turhan [5] showed that leaning wrists on the keyboard, hard keystrokes, extreme wrist joint and thumb positions and working in poor ergonomic design were correlated to pain and development of CTDs. In a study conducted by Karwowski., et al. [6] the results showed that requirements of human-computer interface design significantly affected the operators' postural dynamics. It was concluded that not only the physical, organizational, or psychosocial work environment characteristics, but also the cognitive task characteristics are important for assessment of postural effects in the VDT work. They suggested that relationship between interface design, mental workload and postural dynamics should be carefully considered in future studies aimed at optimizing the human-computer data entry tasks.

Charpe and Kaushik [7] suggested that prevention of injury and illness is the best approach to minimising work related MSDs and comprehensive health care and safety programs can help to reduce corporate sector's workplace injuries and other related expenses. Klussmann., et al. [8] suggested that with regard to musculoskeletal symptoms of the upper extremities, preventive measures at VDT workstations should be focused on neck and shoulder symptoms (e.g. ergonomic measures, breaks to avoid sitting over long periods). They collected the data on MSDs using the Nordic 
Questionnaire, the 12-month prevalence of symptoms of the neck, shoulder region, hand/wrist, or elbow/lower arm was found to be $55 \%, 38 \%, 21 \%$ and $15 \%$ respectively. Also, the duration of VDT work had a significant impact on the frequency of neck symptoms in employees performing such work $>6 \mathrm{~h} / \mathrm{d}$.

\section{Methodology}

The study was conducted in two phases. In the first phase, the tool ESI with 27 items was administered on 200 VDT operators for pilot study. Item Analysis was conducted in order to identify the most appropriate items for the tool. The data was organised to identify the extremes i.e. 25\% highest and 25\% lowest scoring respondents, who were dropped and the data of the middle $50 \%$ of the respondents was taken for item analysis. Most relevant 20 items were retained on the basis of t values (Item Discrimination) and Item Correlation, to ensure that the constructs are different from each other, at the same time being correlated and are suitable for measuring the desired constructs. In the second phase, the tool with 20 items retained after item analysis, was administered on a sample of 1000 VDT operators, out of which 839 subjects were available for the administration for test retest reliability estimation.

\section{Study Findings}

The major factors considered under the items were headaches (specifying the major area and frequency of discomfort) eye dryness, sore eyes and other discomforts, discomforts related to wrists fingers, shoulders and back and other complaints related to workplace.

\begin{tabular}{|c|c|c|c|}
\hline & Items & & Items \\
\hline 1 & $\begin{array}{c}\text { Headaches while working } \\
\text { at the VDT }\end{array}$ & 15 & Pain in midback \\
\hline 2 & $\begin{array}{l}\text { Headache towards the } \\
\text { front of the head }\end{array}$ & 16 & Pain in neck \\
\hline 3 & $\begin{array}{c}\text { Headache on one side of } \\
\text { the head }\end{array}$ & 17 & Pain in shoulders \\
\hline 4 & $\begin{array}{l}\text { Headache on more than } \\
\text { one side of the head }\end{array}$ & 18 & Pain in buttocks \\
\hline 5 & Continuous Headache & 19 & Pain in upper arm \\
\hline 6 & Burning sensation in eyes & 20 & Pain in forearm \\
\hline 7 & Dryness in eyes & 21 & Strain in elbow \\
\hline 8 & $\begin{array}{l}\text { Blurry distant vision when } \\
\text { looking off the VDT }\end{array}$ & 22 & Desire to quit work \\
\hline 9 & Sore eyes & 23 & $\begin{array}{c}\text { Complaints regarding } \\
\text { nature of work }\end{array}$ \\
\hline 10 & $\begin{array}{l}\text { Halos around objects on } \\
\text { the screen }\end{array}$ & 24 & $\begin{array}{c}\text { Complaints regarding } \\
\text { indoor climate }\end{array}$ \\
\hline 11 & Tingling in thumb & 25 & $\begin{array}{c}\text { lack of concentration } \\
\text { in work }\end{array}$ \\
\hline 12 & Tingling in fingers & 26 & Pain in wrists \\
\hline 13 & $\begin{array}{l}\text { Pain in fingers of the } \\
\text { dominant hand }\end{array}$ & 27 & Pain in low back \\
\hline 14 & Pain in upper back & & \\
\hline
\end{tabular}

Table 1: Items in ESI (Charpe and Kaushik, 2014).
The statistical analysis of the items in ESI depicted item correlation value higher than 0.8 and also high item discrimination (with t-values ranging from 3.84 to 10.05 ) and the tool was highly reliable $(r=0.88)[1]$.

Table 2 shows the items retained in Ergonomic Stress Index (ESI) $v 2.0$ after the item analysis of ESI on a sample of 200 subjects in the pilot study. The most relevant 20 items (having t value $>1.75$ ) were retained and it was administered on a sample of 839 respondents in the age group of 29 - 35 years who had been working in IT industry for at least three years to check the reliability estimate of Ergonomic Stress Index (ESI) v2.0.

The item responses were elicited on a Likert-type scale that range from zero (No symptom) to 5 (Unbearably severe), depicting the intensity of the pain symptom.

After item-analysis the set of 20 items was subjected to test of reliability to find out the consistency in providing results after repeated use. The reliability was found by calculating the correlation coefficient (Cronbach's Alpha) of scores.

Test-Retest method was used to estimate the reliability of the research tool over time. The respondents $(n=839)$ were supposed to give their responses on the inventory at an interval of 6 months on the same set of items. The accuracy of this method rests on the assumption that the participants are fundamentally the same during two test periods, thus it was made sure that all the participants were the same for both test periods.

The test retest (0.93) and split halves (0.94) reliability estimate indicated that the tool has very high internal consistency and can be reliable in repeated administrations.

Validity of the inventory: The tool was validated to ensure its dependability in recognising the ergonomic risk factors in the VDT workplace. A number of measures were adopted to establish the content and construct validity viz., creation of items after thorough literature, scanning and brainstorming with panel of 150 experts.

The severity of ergonomic risk factors can be assessed by cumulative scores of any single dimension or the total inventory. Weighted score is assigned for each response opted and the scores obtained by individual respondent on 20 items are added. The final score indicates the level of ergonomic stress imposed on worker at work.

Scoring, norms and Interpretation: z-Score norms were developed for interpretation of the raw scores in order to find out the severity of ergonomic risk factors in the VDT workplace by testing the $\mathrm{z}$-Scores as per norms given in table 4 and 5 .

\section{Discussion and Conclusion}

Studies suggest that addressing the risk factors involved in VDT work is need of the hour, in order to take measures to reduce them and maintain the productivity of the workers. The stressors and 


\begin{tabular}{|c|c|c|c|c|c|c|}
\hline & Items & Mean & SD & t Value & DI & Alpha if item deleted \\
\hline 1 & Headaches while working at the VDT & 3.98 & 0.95 & $1.88^{*}$ & 0.40 & 0.933 \\
\hline 2 & Headache towards the front of the head & 3.72 & 1.26 & $1.81^{*}$ & 0.36 & 0.935 \\
\hline 3 & Headache on one side of the head & 3.74 & 1.15 & $1.79^{*}$ & 0.48 & 0.936 \\
\hline 5 & Pain in wrists & 3.30 & 1.28 & $2.70^{* *}$ & 0.40 & 0.932 \\
\hline 6 & Burning sensation in eyes & 3.86 & 1.01 & $2.44^{* *}$ & 0.36 & 0.932 \\
\hline 7 & Dryness in eyes & 1.94 & 1.51 & $2.42^{* *}$ & 0.72 & 0.932 \\
\hline 8 & Pain in low back & 2.56 & 1.24 & $2.32^{*}$ & 0.68 & 0.933 \\
\hline 9 & Sore eyes & 4.06 & 0.86 & $1.83^{*}$ & 0.40 & 0.932 \\
\hline 10 & Halos around objects on the screen & 3.28 & 1.47 & $1.97^{*}$ & 0.40 & 0.934 \\
\hline 11 & Tingling in thumb & 2.42 & 1.35 & $1.89^{*}$ & 0.36 & 0.934 \\
\hline 12 & Tingling in fingers & 3.22 & 1.58 & $1.89^{*}$ & 0.36 & 0.935 \\
\hline 13 & Pain in fingers of the dominant hand & 2.74 & 1.15 & $3.37^{* *}$ & 0.56 & 0.934 \\
\hline 14 & Pain in upper back & 3.22 & 1.13 & $3.11^{* *}$ & 0.36 & 0.935 \\
\hline 15 & Pain in midback & 3.00 & 1.19 & $3.31^{* *}$ & 0.44 & 0.934 \\
\hline 16 & Pain in neck & 3.16 & 1.26 & $3.16^{* *}$ & 0.64 & 0.935 \\
\hline 17 & Pain in shoulders & 2.08 & 1.06 & $2.20^{*}$ & 0.44 & 0.935 \\
\hline 18 & Pain in upper arm & 2.46 & 1.21 & $2.54^{* *}$ & 0.36 & 0.935 \\
\hline 19 & Pain in forearm & 3.12 & 1.35 & $3.05^{* *}$ & 0.48 & 0.935 \\
\hline 20 & Strain in elbow & 2.66 & 1.34 & $2.92^{* *}$ & 0.52 & 0.935 \\
\hline
\end{tabular}

Table 2: Items in ergonomic stress index (ESI) v2.0.

\begin{tabular}{|c|c|}
\hline Method & Reliability \\
\hline Test-Retest & 0.93 \\
\hline Split Halves & 0.94 \\
\hline
\end{tabular}

Table 3: Reliability estimate of the ergonomic stress index (ESI) v2.0.

\begin{tabular}{|c|c|c|c|}
\hline & Mean: 94.56 & SD: $\mathbf{\pm 4 . 6 8}$ & $\mathbf{N}=\mathbf{8 3 9}$ \\
\hline Raw Score & z-Score & Raw Score & z-Score \\
\hline 74 & -4.39 & 95 & 0.09 \\
\hline 75 & -4.17 & 96 & 0.30 \\
\hline 76 & -3.96 & 97 & 0.52 \\
\hline 77 & -3.75 & 98 & 0.73 \\
\hline 78 & -3.53 & 99 & 0.96 \\
\hline 79 & -3.32 & 100 & 1.16 \\
\hline 80 & -3.11 & 101 & 1.37 \\
\hline 81 & -2.89 & 102 & 1.58 \\
\hline 82 & -2.68 & 103 & 1.80 \\
\hline 83 & -2.47 & 104 & 2.01 \\
\hline 84 & -2.25 & 105 & 2.23 \\
\hline 85 & -2.04 & 106 & 2.44 \\
\hline 86 & -1.82 & 107 & 2.65 \\
\hline 87 & -1.61 & 108 & 2.87 \\
\hline 88 & -1.40 & 109 & 3.08 \\
\hline 89 & -1.18 & 110 & 3.29 \\
\hline 90 & -0.97 & 111 & 3.51 \\
\hline 91 & -0.76 & 112 & 3.72 \\
\hline 92 & -0.54 & 113 & 4.00 \\
\hline 93 & -0.33 & 114 & 4.15 \\
\hline 94 & -0.11 & 115 & 4.36 \\
\hline
\end{tabular}

Table 4: z-score norms for ergonomic stress index (ESI) v2.0. 


\begin{tabular}{|c|c|c|}
\hline Range of Raw Scores & Range of z scores & Severity of Ergonomic Risk Factors \\
\hline Above 115 & +4.36 and Above & Extremely High \\
\hline $108-115$ & +2.87 to ++4.36 & Very High \\
\hline $100-107$ & +1.16 to +2.65 & High \\
\hline $90-99$ & -0.97 to +0.96 & Moderate \\
\hline $82-89$ & -2.68 to -1.18 & Low \\
\hline $74-81$ & -4.39 to -2.89 & Very Low \\
\hline Below 74 & -2.89 and Below & Extremely Low \\
\hline
\end{tabular}

Table 5: Norms for interpretation of z-score and ergonomic risk factor severity.

work conditions, which contain these risks, are always present when the requirements exceed the worker's threshold limits for performing tasks. The major reason of lost productivity is quoted as the onset of musculoskeletal disorders in the early stages of job demanding prolonged working on VDTs. Studies reveal that with the increasing number of health risk factors the percentage of employees reporting work limitations have also increased. The intervention strategies in the workplace for the reduction of both exposure and effect should focus upon factors within the work organization as well as actively involving the individual worker.

If the symptoms persist for many consecutive days, they affect work and other activities; it becomes important that a therapy is sought. The workplace conditions should be justified in terms of the safety and well being of the workers who are going to accomplish work in it. Prevention of injury and illness is, obviously, the best approach, but comprehensive health care and safety programmes should be designed to reduce corporate sector's workplace injuries, absenteeism or related expenses.

Ergonomic Stress Index v2.0 (ESI v2.0) can be used to assess the level of severity of ergonomic risk factors at the VDT workplace and appropriate strategies can be further designed to prevent musculoskeletal problems and check decline in worker's efficiency and productivity.

\section{Bibliography}

1. Charpe NA and Kaushik V. "Ergonomic Stress Index for Video Display Terminal Operators". In: Vinay D (eds). Conference Proceedings HWWE ERG02012: Safety for All (2014).

2. Bridger RS. "A Guide to Active Work in the Modern Office: Homo Sedens in the $21^{\text {st }}$ Century". CRC Press (2019).

3. Charpe NA and Gupta S. "Occupational Stress Inventory (OSI) for Ergonomic Evaluation of Work Stress Among VDT Operators". In: Arezes P. (eds) Advances in Safety Management and Human Factors. AHFE 2018. Advances in Intelligent Systems and Computing, volume 791. Springer, Cham (2019).

4. Shuval K and Donchin M. "Prevalence of upper extremity musculoskeletal symptoms and ergonomic risk factors at a Hi-Tech company in Israel". International Journal of Industrial Ergonomics 35.6 (2005): 569-581.
5. Turhan Celil., et al. "Ergonomic Risk Factors for Cumulative Trauma Disorders in VDU Operators". International Journal of Occupational Safety and Ergonomics 14.4 (2008): 417-422.

6. Karwowski W., et al. "The effects of computer interface design on human postural dynamics". Ergonomics 37.4 (2007): 703724.

7. Charpe NA and Kaushik V. "Computer Vision Syndrome (CVS): Recognition and Control in Software Professionals". Journal of Human Ecology 28.1 (2009): 67-69.

8. Klussmann A., et al. "Musculoskeletal symptoms of the upper extremities and the neck: A cross-sectional study on prevalence and symptom-predicting factors at visual display terminal (VDT) workstations". BMC Musculoskeletal Disorders 9.1 (2008): 96.

\section{Assets from publication with us}

- Prompt Acknowledgement after receiving the article

- Thorough Double blinded peer review

- Rapid Publication

- Issue of Publication Certificate

- High visibility of your Published work

Website: https://www.actascientific.com/

Submit Article: https://www.actascientific.com/submission.php Email us: editor@actascientific.com

Contact us: +919182824667 